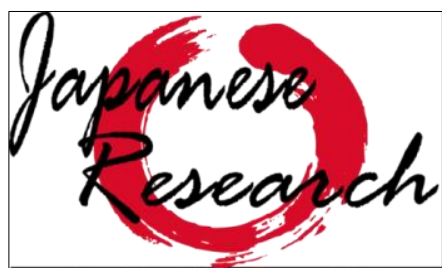

on Linguistics, Literature and Culture
Japanese Research on Linguistics, Literature, and Culture

Vol. 1 No. 2 May 2019, Hal. 198-225

ISSN online: $2655-4836$

http://publikasi.dinus.ac.id/index.php/irllc/article/view/3008/1708

DOI : $10.33633 /$ ir.v1i2.3008

Published by Universitas Dian Nuswantoro, Semarang

\title{
Implikatur Percakapan pada Respon Verbal Tokoh Haruko dalam Drama Nihonjin no Shiranai Nihongo Karya Yoshihiro Izumi
}

\author{
Dewi Karunia Widiyaningrum \\ Universitas Dian Nuswantoro \\ dewikaruniawidiya@gmail.com
}

Article History: Submitted date 2019-09-24; Accepted date 2019-10-07; Published date 2019-10-17

\begin{abstract}
The core problem of this study is to investigate the types of implicature used by Haruko, the main character, as verbal respond in he drama titled Nihonjin no Shiranai Nihongo. This study used cooperative principles theory by Grice to analyze the implicature. The study is to aimed to describe the verbal respond which the main character used in the drama, also to find the implicit meaning in the conversation. The study is using descriptive qulitative methode. The data are obtioned from the Haruko's verbal respond which is violating the cooperative principle maxim by Grice. This study is a pragmatic study, so the analysis will be analyzed by the context. There are 23 datas obtioned from Haruko's verbal respond which is violating the cooperative maxim by Grice. From those datas, there are 1 utteranc violating the maxim of quality, 11 utterances violating the maxim of quantity, 13 utterances violating the maxim of relation, and 6 utterances violating the maxim of manner. From this study is also found that there is utterances from Haruko's verbal respond that is violating more than one maxim. The violating maxim of ach utterance have a different meaning. Based on the analysis that have been dobe, the aim of the conversational implicature in the drama to give or ask some information, to hide something, to avoid conversation, to express anger, to increase self confident, to mock someone, to share some stories, to share some information in polite way.
\end{abstract}

Keywords : implicature, maxim, cooperative principle

\begin{abstract}
Abstrak
Rumusan masalah penelitian ini adalah implikatur apa yang terdapat pada respon verbal tokoh Haruko dalam drama Nihonjin no Shiranai Nihongo. Pengkajian implikatur menggunakan teori prinsip kerja sama Grice. Penelitian ini bertujuan untuk mendeskripsikan implikatir yang terdapat pada respun verbal tokoh Haruko dalam drama Nihonjin no Siranai Nihongo, serta mencari tahu makna tersirat yang terkandung dalam implikatur percakapan tersebut. Metode yang digunakan pada penelitian ini adalah
\end{abstract}



metode deskriptif kualitatif. Data yang akan dianalisis berupa respon verbal tokoh Haruko sebagai tokoh utama yang melanggar prinsip kerja sama Grice. penelitian ini merupakan studi pragmatik, maka dari itu tuturan dianalisis berdasarkan konteksnya.Terdapat 23 respon verbal Haruko yang melanggar maksim-maksim prinsip kerja sama Grice. Dalam 23 tuturan tersebut ada 1 tuturan yang melanggar maksim kualitas, 11 tuturan melanggar maksim kuantitas, 13 tuturan melanggar maksim relevansi, dan 6 tuturan melanggar maksim cara. Tidak hanya ditemukan pelanggaran terhadap satu maksim, melainkan ditemukan juga tuturan yang melanggar dua maksim prinsip kerja sama Grice. Pelanggaran maksim-maksim tersbut memiliki makdus dan tujuan tertentu yang berbedabeda. Berdasarkan analisis data yang telah dilakukan, implikatur percakapan dilakukan dengan tujuan untuk memberikan atau meminta informasi, menutupi sesuatu, mengalihkan pembicaraan, mengungkapkan kemarahan, meningkatkan kepercayaan diri, mengejek, berbagi cerita, dan menyampaikan sesuatu secara halus.

Kata kunci : implikatur, maksim, prinsip kerja sama

\section{Pendahuluan}

Dalam berkomunikasi menggunakan bahasa, selalu mempunyai aturan tersendiri. Tetapi pada kehidupan sehari - hari sering kali manusia tidak mematuhi aturan tersebut. Karena demi menghidupkan suasana saat berkomunikasi, baik penutur maupun mitra tutur harus melanggar aturan dalam berbahasa. Bahkan terkadang kita sering menemukan penggunaan bahasa yang tidak sesuai dengan kaidah penggunaan bahasa tersebut. Faktor inilah yang mendorong pengkajian bahasa di mana bahasa tidak hanya berkutat pada aturan struktural melainkan berhubungan dengan kondisi dan konteks kebahasaan yang ada. Kajian ini sangat sering ditemukan dalam praktik komunikasi sehari-hari antara penutur dan mitra tutur. Pengkajian bahasa yang berhubungan dengan konteks kebahasaan disebut kajian pragmatik.

\subsection{Kajian Teoretis}

Menurut George Yule (1996:3) “Pragmatik adalah studi tentang makna yang disampaikan oleh penutur (atau penulis) dan ditafsirkan oleh pendengar (atau pembaca)." Dari definisi tersebut, dapat diketahui bahwa pragmatik adalah cabang ilmu yang mengkaji bahasa dengan mengkaitkan pada konteks kebahasaan. Salah satu cabang kajian prangmatik adalah implikatur percakapan. Dapat kita pahami bahwa pada setiap percakapan yang dilakukan oleh 
penutur dan mitra tutur akan mengandung sebuah maksud. Maksud dari percakapan tersebut dapat berbeda dengan struktur bahasa yang digunakan. Suatu maksud dari penggunaan bahasa sering kali mengandung maksud lain yang tersembunyi atau tersirat. Pada saat seperti inilah sangat tepat untuk menggunakan kajian pragmatik implikatur percakapan.

Menurut Paul Grice dalam bukunya Studies in the Way of Words (1991:26) "Make your conversational contribution such as is required, at the stage at wich is occurs, by the accepted purpose or direction of the talk exchange in wich your enganged." Penutur maupun mitra tutur harus mematuhi prinsip kerja sama dan maksim - maksimnya agar komunikasi dapat berjalan dengan lancar. Grice membagi maksim-maksim prinsip kerja sama menjadi empat maksim yaitu, maksim kuantitas, maksim kualitas, maksim relevansi dan maksim cara. Apabila maksimmaksim itu dilanggar maka akan terjadi implikatur. Dalam beberapa kasus, implikatur digunakan untuk tujuan tertentu, misalnya untuk memperhalus tuturan, untuk tidak menyinggung perasaan mitra tutur, dan untuk menuturkan perintah secara lebih sopan.

Menggunakan implikatur pada percakapan berarti menyatakan suatu maksud tertentu secara tidak langsung. Implikatur sebuah tuturan dapat dipahami dengan cara meneliti konteks yang dipakai pada penuturan. Dalam penelitian ini dikaji implikatur percakapan yang terjadi akibat pelanggaran dari maksim-maksim prinsip kerja sama Grice. Sumber data penelitian diambil dari Drama Jepang berjudul Nihonjin no Shiranai Nihongo karya Yoshihiro Izumi. Film ini dijadikan data kajian karena percakapan dalam film ini menggunakan bahasa sehari-hari (informal). Dalam film ini sering terjadi percakapan yang mengandung implikasi. Maksud yang diimplikasikan memiliki ciri khas tentang konfik yang dialami oleh tokoh.

\subsection{Metode Penelitian}

Sumber data penelitian ini berupa drama Jepang berjudul Nihonjin no Shiranai Nihongo yang berjumlah 12 episode. Data yang digunakan adalah percakapan antara tokoh utama, Haruko dan tokoh lain. Drama tersebut dijadikan sumber data pada penelitian ini karena percakapan antar tokoh menggunakan bahasa sehari-hari atau informal, dan dalam percakapan tersebut banyak tuturan tokoh utama yang mengandung implikatur. 
Data penelitian ini berupa percakapan antara Haruko sebagai tokoh utama dan lawan bicaranya. Penulis melihat drama Nihonjin no Shiranai Nihongo secara keseluruhan, kemudian mengutip respon verbal tokoh Haruko sebagai tokoh utama yang mengandung implikatur yang dapat dijadikan data penelitian lalu menganalisis data tersebut sesuai fokus penelitian yaitu berdasarkan teori prinsip kerja sama milik Grice. Setelah data terkumpul, penulis menganalisis data sebagai berikut :

1. Mengidentifikasi tuturan tokoh Haruko yang melanggar prinsip kerja sama Grice.

2. Mengkategorikan pelanggaran maksim tersebut ke dalam pelanggaran maksim kuantitas, maksim kualitas, maksim relevansi, dan maksim cara.

3. Menganalisis implikatur beserta alasan.

4. Membuat simpulan.

\section{Hasil dan Pembahasan}

Data penelitian ini berupa dialog antara tokoh Haruko sebagai tokoh utama dengan tokoh lain. Kemudian menganalisis tuturan Haruko yang mengandung implikatur menggunakan teori prisip kerja sama Grice. Ditemukan tuturan dengan pelanggaran maksim tunggal atau tuturan yang melanggar satu maksim prinsip kerja sama Grice dan pelanggaran maksim ganda atau tuturan yang melanggar dua maksim prinsim kerja sama Grice.

\section{Pelanggaran maksim tunggal:}

\section{Data 1}

\section{Data 1 :}

Haruko : "Jya, mono no kazoekata ni tsuite shitsumon aru hito, Sensei ga nandemo oshiete agemasu." (1)

Baik, siapa yang ingin bertanya mengenai satuan hitung benda, Ibu akan memberitahu apapun.

Diana : (sambil mengacungkan tangan) "Suturoo wa?" (2) Sedotan?

Haruko : "Tatte iite.!" (3) Berdiri, lalu katakanlah.

Situasi percakapan :

Percakapan berlangsung di dalam kelas saat kegiatan belajar mengajar. Di dalam kelas tersebut terdapat sembilang orang murid yang semuanya orang asing. Haruko sebagai guru 
(Sensei) sedang memberikan pelajaran bahasa Jepang mengenai satuan hitung benda (mono no kazoekata) kepada murid-muridnya. Setelah menulis di papan tulis, Haruko membiarkan muridnya bertanya pertaanyaan yang berkaitan dengan satuan hitung benda. Salah satu murid bernama Diana yang berkebangsaan Rusia bertanya mengenai satuan hitung untuk sebuah sedotan.

Analisis :

Tuturan Haruko (3) : "Tatte, iite!" dapat dikatakan melanggar maksim Cara dan maksim relevansi. Haruko membiarkan muridnya bertanya mengenai satuan hitung, kemudian Diana bertanya kepada Haruko tentang satuan hitung untuk sebuah sedotan (2) : "Suturoo wa?". Untuk pertanyaan itu Diana memerlukan jawaban berupa satuan hitung untuk sebuah sedotan yaitu 'ikkou'. Namun Haruko tidak memberikan informasi yang dibutuhkan Diana, melainkan menjawab dengan tuturan (3) : "Tatte, iite!" yang artinya 'Berdiri, lalu katakanlah'. Pada tuturan ini Haruko menggunakan implikatur percakapan yang melanggar maksim Cara karena informasi yang dia berikan tidak jelas dan maksim relevansi karena informasi yang dia berikan tidak relevan atau tidak berhubungan dengan pertanyaan Diana.

Pelanggaran maksim Cara dan maksim relevansi tersebut meiliki alasan bahwa Haruko ingin memberitahu Diana Cara bertanya di dalam kelas yang tepat yaitu dengan berdiri terlebih dahulu kemudian menanyakan pertanyaannya.

\section{Data 2}

Haruko : "Hoka ni shitsumon aru hito." (4)

Siapa yang mau bertanya lagi?

Paul : (berdiri) "'Maguro' tte donna ji dakke?” (5)

'Maguro' itu hurufnya seperti apa?

Haruko : :Eh? Kanji tte koto?” (6)

Eh? Maksudnya huruf kanji?

Situasi percakapan :

Percakapan berlangsung di dalam kelas saat Haruko sedang memberikan pelajaran bahasa Jepang kepada murid-murid yang mana semuanya adalah orang asing. Pelajaran yang sedang diberikan saat itu adalah satuan hitung benda dalam bahasa Jepang, namun karena 
Haruko tidak bisa menjawab pertanyaan-pertanyaan muridnya mengenai satuan hitung benda, pembahasan pun berubah. Salah satu murid bernama Paul bertanya pada Haruko mengenai bagaimana huruf untuk "Maguro" (ikan tuna).

Analisis :

Tuturan Haruko (6) : “Eh? Kanji tte koto?" dapat dikatakan melanggar maksim relevansi. Saat Paul bertanya dengan tuturan (5) : “'Maguro' tte donna ji dakke?" seharusnya Haruko memberikan jawaban berupa bagaimana huruf kanji untuk maguro atau tuna. Namun Haruko tidak langsung memberikan jawaban yang diinginkan Paul, melainkan memberikan pertanyaan kepada Paul dengan tuturan (6) : “Eh? Kanji tte koto?" yang artinya "Eh? Maksudnya huruf kanji?". Pada tuturan ini haruko menggunakan implikatur percakapan yang melanggar maksim relevansi karena jawaban yang diberikan Haruko tidak relevan atau tidak berhunungan dengan pertanyaan yang diberikan oleh Paul.

Pelanggaran maksim relevansi tersebut meiliki alasan bahwa Haruko ingin memastikan bahwa huruf untuk maguro yang maksud oleh Paul adalah huruf kanji. Karena Paul memberikan pertanyaan di luar bab yang sedang diajarkan Haruko pada saat itu, maka Haruko sedikit bingung dengan pertanyaan Paul.

\section{Data 3}

Jack : :Shitsumon shitemo yoroshii desu ka?" (7) Bolehkah saya bertanya?

Haruko : "Hai." (8) Boleh.

Jack : "Osashimi wo taberu toki ni tsukau, oshoyuu wo ireru, shikakukute, shikiri no aru osara no namae wa nan desu ka?" (9)

Piring untuk tempat kecap asin yang berbentuk persegi empat, ada pembatas di tengahnya, dan digunakan saat memakan sashimi, namanya apa?

Haruko : :Shikakukute, shikiri no aru osara wa.... iya.. namae tte iwaretemo.." (10)

Piring berbentuk persegi empat dan ada pembatas di tengahnya.. em.. namanya..

Situasi percakapan : 
Percakapan terjadi di dalam kelas saat Haruko sedang memberikan pelajaran bahasa Jepang kepada murid-muridnya yang mana semuanya adalah orang asing. Salah satu murid bernama Jack bertanya kepada Haruko mengenai nama piring tempat saus yang digunakan saat memakan sashimi. Dia menjelaskan ciri-ciri dan bentuk piring itu seCara rinci kepada Haruko.

Analisis :

Tuturan Haruko (10) : "Shikakukute, shikiri no aru osara wa.... iya.. namae tte iwaretemo.." dapat dikatakan melanggar maksim kuantitas dan maksim Cara._Jack memberikan pertanyaan kepada haruko dengan tuturan (9) : "Osashimi wo taberu toki ni tsukau, oshoyuu wo ireru, shikakukute, shikiri no aru osara no namae wa nan desu ka?", yang artinya "piring untuk tempat kecap asin yang berbentuk persegi empat, ada pembatas di tengahnya, dan digunakan saat memakan sashimi, namanya apa?", dengan maksud ingin mendapatkan jawaban berupa nama piring yang ditanyakannya. Haruko sedikit bingung dengan ciri-ciri yang disebutkan Jack dengan sangat rinci. Dia bisa membayangkan piring itu seperti apa, juga dia pernah melihat piring itu, tetapi tidak mengatahui namanya. Dengan begitu haruko menjawab pertanyaan Jack dengan tuturan (10) : "Shikakukute, shikiri no aru osara wa.... iya.. namae tte iwaretemo.." yang artinya "Piring bebrbentuk persegi empat dan ada pembatas di tengahnya.. em.. namanya..". Pada tuturan ini Haruko melanggar maksim kuantitas karena jawaban yang diberikan tidak informatif dan maksim Cara karena jawaban yang diberikan tidak jelas dan tidak singkat.

Pelanggaran maksim kuantitas dan maksim Cara tersebut meiliki alasan bahwa Haruko tidak mengatahui nama piring yang ditanyakan Jack, tetapi dia tidak ingin terlihat tidak tahu. Jika dia menjawab dengan kata "tidak tahu", maka murid-muridnya akan meragukan dia sebagai seorang guru.

\section{Data 4}

Diana : : "Otabekudasai." (11) Otabekudasai (tolong makan).

Haruko : : "Um.. 'Taberu' no sonkeigo wa 'meshiagaru' ne." (12) Em.. Bahasa sopan untuk taberu (makan) adalah meshiagaru.

Diana : :Otabekudasai wa machigai desu ka?” (13) 
Apakah otabekudasai sala?

Haruko : : "Mm.. Maa yoku tsukau kedo, seikaku ni wa machigatta iikata

kana.. ano ne, keigo ni wa kotoba ni yotte ironnatsukaikata ga aru no." (14)

Mm.. Itu sering digunakan, tetapi sebenarnya mungkin salah

pengucapan.. em, di dalam bahasa halus itu, ada berbagai

macam penggunaan sesuai dengan katanya.

Situasi percakapan :

Percakapan terjadi di dalam kelas saat Haruko sedang menjelaskan bahasa sopan (keigo) pada murid-muridnya. Haruko menjelaskan penggunaan bahasa sopan untuk kata kerja (doushi) yaitu dengan menambahkan o di awal kata dan ni narimasu di akhir kata. Setelah menjelaskan, Haruko menyuruh murid-muridnya membuat contoh kalimat dengan menggunakan keigo. Lalu murid bernama Diana mengatakan Otabekudasai (sialakan makan/tolong makan). Karena kalimat itu kurang tepat, Haruko menjelaskan bahwa bentuk sopan untu 'taberu' (makan) adalah 'meshiaagaru'. Lalu Diana bertanya pada Haruko apakah otabekudasai itu salah.

Analisis :

Tuturan Haruko (14) : Mm.. Maa yoku tsukau kedo, seikaku ni wa machigatta iikata kana.. ano ne keigo ni wa kotoba ni yotte ironnatsukaikata ga aru no." dapat dikatakan melanggar maksim kuantitas dan maksim kualitas. Pertanyaan Diana pada tuturan (13) : “Otabekudasai wa machigai desu ka?" yang artinya "apakah otabekudasai salah?", hanya membutuhkan jawaban 'salah' atau 'tidak salah'. Namun Haruko tidak menjawab salah atau tidak salah melainkan memberikan penjelasan mengenai penggunaan bahasa sopan (keigo) yang berbeda-beda menurut kata masing-masing "Mm.. Maa yoku tsukau kedo, seikaku ni wa machigatta iikata kana.. ano ne keigo ni wa kotoba ni yotte ironnatsukaikata ga aru no." yang artinya "Mm.. Itu sering digunakan, tetapi sebenarnya mungkin salah pengucapan.. em, di dalam bahasa halus itu, ada berbagai macam penggunaan sesuai dengan katanya." Tuturan ini melanggar maksim kuantitas karena jawaban yang diberikan Haruko lebih infrormatif dari yang diinginkan Diana. Haruko menggunakan kata "kana" (mungkin) pada penjelasannya yang berarti dia tidak yakin dengan kebenaran dari penjelasan yang dia berikan. Hal ini menyebabkan Haruko melanggar maksim Kualitas. 
Pelanggaran maksim kuantitas dan maksim kulaitas tersebut meiliki alasan bahwa Haruko ingin memberikan penjelasan mengenai bentuk sopan kepada Diana agar dia lebih paham mengapa kalimat otabekudasai tidak tepat.

\section{Data 5}

Haruko : "Paul! Kyou, shukudai minna no sanbai dakara ne!" (15)

Paul! Hari ini kamu mendapatkan pekerjaan rumah tiga kali lipat dari yang lain, ya!

Paul : "Maji ka yo?" (16)

Benarkah?

Haruko : : "Sensei ni taishite wa keigo deshou!" (17)

Bukankah harusnya menggunakan bahasa sopan pada guru?

Situasi percakapan :

Percakapan terjadi di dalam kelas saat Haruko sedang menjelaskan pelajaran bahasa Jepang mengenai keigo (bahasa sopan). Haruko menjelaskan pada murid-muridnya bahwa bentuk keigo untuk kata kerja iru, iku dan kuru adalah irassharu. Kemudian murid bernama Paul membuat lelucon dengan kalimat irassharu yang membuat Haruko marah.

Analisis :

Tuturan Haruko (17) : "Sensei ni taishite wa keigo deshou!" bisa dikatakan melanggar maksim relevansi. Haruko marah kepada Paul karena dia memotong penjelasan Haruko dengan melontarkan lelucon, lalu Haruko memberikan hukuman kepada Paul untuk mengerjakan pekerjaan rumah tiga kali lipat dari yang lain. Paul yang merasa itu tidak adil memprotes dengan mengatakan tuturan (16) : “Maji ka yo?" yang artinya "Benarkah?”. Jawawan yang diberikah Haruko seharusnya berupa "benar" atau "tidak". Namun pada tuturan (16) Paul menggunakan bahasa tidak formal, padahal jika berbiCara dengan guru harusnya paul menggunakan keigo. Haruko kemudian memberikan jawaban dengan tuturan (17) : "Sensei ni taishite wa keigo deshou!" yang artinya "Bukankah harusnya menggunakan bahasa sopan pada guru?". Tuturan ini melanggar maksim relevansi karena jawaban yang diberikan Haruko tidak relevan atau tidak berhubungan dengan pertanyaan yang diberikan Paul. 
Pelanggaran maksim relevansi tersebut memiliki alasan bahwa Haru ingin mengingatkan Paul untuk tidak menggunakan bahasa tidak formal pada guru, melainkan menggunakan keigo (bahasa sopan).

\section{Data 6}

Diana : "Nihonjin, naze machigatta keigo wo tsukau no?” (18) Mengapa orang jepang menggunakan bahasa sopan yang salah?

Haruko : : (menggumam) "lya.. Naze tte.." (19)

(menggumam) Eh.. Kenapa ya..

Diana : :Shinjirarenai!" (20)

Tidak bisa dipercaya!

Situasi percakapan :

Percakapan terjadi di sebuah restoran keluarga tempat Diana bekerja. Haruko membawa semua muridnya ke restoran itu untuk menunjukkan bagaimana perbedaan bahasa sopan yang benar dan baito keigo atau bahasa sopan yang sering digunakan oleh para pekerja paruh waktu di restoran. Menurut penjelasan Haruko semua keigo yang digunakan oleh para pekerja paruh waktu itu berbeda dengan keigo yang benar atau keigo yang ada di buku pelajaran. Diana menjadi marah karena dia berpikir bahwa orang Jepang menggunakan keigo yang salah dengan sengaja.

Analisis :

Tuturan Haruko (19) : "lya.. Naze tte.." bisa dikatakan melanggar maksim Cara. Pertanyaan Diana pada tuturan (18) : "Nihonjin, naze machigatta keigo wo tsukau no?" yang artinya "Mengapa orang jepang menggunakan bahasa sopan yang salah?" membutuhkan jawaban berupa alasan mengapa orang Jepang menggunakan bahasa yang salah. Haruko berpikir bahwa menggunakan baito keigo bukanlah suatu kesalahan, maka dia bingung memberikan jawaban untuk pertanyaan Diana. Jawaban Haruko (19) : "Iya.. Naze tte.." yang artinya "Eh.. Kenapa ya" justru membuat Diana marah, lalu membentak Haruko dengan mengatakan tuturan (20) : "Shinjirarenai!" yang artinya "Tidak bisa dipercaya!". Tuturan Haruko (19) : "Iya.. Naze tte.." melanggar maksim Cara karena yang dia katakan tidak jelas. Bukannya 
memberikan alasan yang dibutuhkan Diana, dia malah menjawab dengan gumaman yang tidak kelas.

Pelanggaran maksim Cara tersebut memiliki alasan bahwa Haruko kebingungan menjawab pertanyaan Diana karena menurutnya baito keigo bukan bahasa yang salah, melainkan hanya berbeda penggunaan berdasarkan tempatnya.

\section{Data 7}

Kinrei : : "Mezurashiku yoshuu shite kita no?” (21) Apakah kamu menyiapkan pelajaran dengan tidak biasa?

Haruko : : "Mezurashiku tte iu na!" (22) Jangan bilang 'tidak biasa'!

Situasi percakapan :

Percakapan terjadi di dalam kelas saat Haruko sedang memberikan pelajaran mengenai dua Cara membaca huruf kanji di Jepang, yaitu kunyomi (Cara baca Cina) dan onyomi (Cara baca Jepang). Saat murid bernama Jack bertanya mengapa di Jepang mempunyai dua macam Cara membaca huruf kanji, Haruko kesulitan menjawab. Lalu murid bernama Kinrei menyindir Haruko.

Analisis :

Tuturan Haruko (22) : "Mezurashiku tte iu na!" bisa dikatakan melanggar maksim relevansi dan Cara. Kinrei menyindir Haruko dengan pertanyaan pada tuturan (21) : "Mezurashiku yoshuu shite kita no?” yang artinya "Apakah kamu menyiapkan pelajaran dengan tidak biasa?". Dalam hal ini, Kinrei membutuhkan jawaban berupa "Ya" atau "Tidak." Namun Haruko tidak menjawab dengan jawaban yang dibutuhkan Kinrei melainkan memberikan respon berupa larangan pada Kinrei di tuturan (22) : "Mezurashiku tte iu na!" yang artinya “Jangan bilang 'tidak biasa'!". Tuturan ini melanggar maksim relevansi karena respon yang diberikan Haruko tidak berhubungan dengan pertanyaan Kinrei. Yang dibutuhkan Kinrei adalah jawaban "Ya" atau "Tidak", tetapi Haruko justru merespon dengan kalimat larangan. Tuturan ini juga melanggar maksim Cara karena respon yang diberikan Haruko mengandung ketaksaan atau makna yang tidak jelas mengapa Haruko melarang Kinrei mengatakan kata "Mezurashii". 
Pelanggaran maksim relevansi dan maksim Cara tersebut memiliki alasan bahwa Haruko marah dan tersinggung oleh sindiran yang diberikan Kinrei. Dia menyindir Haruko karena tidak menyiapkan pelajaran dengan baik. Haruko yang merasa tersinggung lalu memberikan kalimat larang kepada Kinrei agar terlihat tegas di depan muridnya.

\section{Data 8}

Haruko : "Nee Ruuka. Watashi, manga gaku no tetsudatte ageyou ka?"

(23)

Hei, Luke. Haruskah aku membantumu dalam menulis komik?

Kinrei : : "Nande haruko ga tetsudau no yo?" (24)

Kenapa kamu harus membantu?

Haruko : : "Wakannai kana. Motto ureru manga wo kaku ni wa nihonjin no

kimochi wo wakattokanakya." (25)

Kamu tidak mengerti ya. Untuk bisa menulis komik yang lebih

laris dijual itu, harus mengerti perasaan orang Jepang.

Situasi percakapan :

Percakapan terjadi di dalam kelas saat haruko sedang memberikan penjelasan mengenai Cara membaca huruf kanji di Jepang. Haruko menyuruh murid bernama Luke untuk menuliskan contoh huruf kanji. Tapi contoh yang diberikan oleh Luke salah. Saat Haruko memberi tah bahwa contoh yang diberikan Luke salah, dia membantah karena kanji itu dipakai di dalam kebanyakan komik Jepang. Dia menunjukkan huruf kanji yang ada dalam komik yang ditulisnya. Lalu Haruko menjelaskan bahwa yang ada dalam komik itu tidak tepat karena menurutnya komik itu hanya hobby untuk Luke, sedangkan para penulis komik profesional yang bisa menghasilkan uang dari komik yang mereka tulis biasanya menggunakan kanji yang benar. Analisis :

Tuturan Haruko (25) : "Wakannai kana. Motto ureru manga wo kaku ni wa nihonjin no kimochi wo wakattokanakya." bisa dikatakan melanggar maksim kuantitas. Haruko menawarkan bantuan kepada Luke agar dia bisa membuat komik yang benar. Namun murid bernama Kinrei tidak mengeri mengapa Haruko harus membantu Luke. Dia bertanya "Kenapa kamu harus membantu?", kemudian Haruko menjawab dengan tuturan (25) yang artinya, "Kamu tidak mengerti ya. Untuk bisa menulis komik yang lebih laris dijual itu, harus mengerti 
perasaan orang Jepang." tuturan ini melanggar maksim kuantitas karena Jawaban yang diberikan Haruko lebih informatif dari yang seharusnya dibutuhkan Kinrei. Haruko menambahkan kalimat "wakannai kana" yang artinya "kamu tidak mengerti, ya", kalimat itu adalah informasi yang tidak dibutuhkan Kinrei, seharusnya dia hanya menjawab "Motto ureru manga wo kaku ni wa nihonjin no kimochi wo wakattokanakya." saja.

Pelanggaran maskim kuantitas tersebut mempunyai alasan bahwa Haruko ingin mempertegas kepada Kinrei bahwa dia harus membantu Luke karena dia orang Jepang. Menurutnya komik Jepang harus sesuai dengan perasaan dan budaya Jepang.

\section{Data 9}

\begin{tabular}{|c|c|}
\hline Ellen & : “Haruko!" (26) \\
\hline & Haruko! \\
\hline Haruko & : "Ellen!" (27) \\
\hline & Ellen! \\
\hline Ellen & : "Doujinshi de bottakuru tsumori ne?" (28) \\
\hline & Kamu bermaksud membantu Luke ya? \\
\hline Haruko & : “Chotto.. Nandemonai kara, nandemonai. Sst!” (29) \\
\hline & Em.. Bukan apa-apa kok, bukan apa-apa. Sst! \\
\hline
\end{tabular}

Situasi percakapan :

Percakapan berlangsung di sebuah kafe tempat Luke, murid Haruko bekerja. Sebelumnya, Luke meminta bantuan kepada Haruko untuk mengajarinya Cara ,engungkapkan perasaan kepada wanita. Luke dan wanita yang disukainya bekerja di tempat yang sama. Haruko yang semula bingung dengan permintaan Luke, akhirnya memutuskan untuk membantunya. Di dalam kafe, dia bertemu dengan muridnya yang lain yaitu Ellen. Analisis :

Tuturan Haruko (29) : “Chotto.. Nandemonai kara, nandemonai. Sst!" bisa dikatakan melanggar maksim relevansi dan Cara. Ellen bertanya pada Haruko (28) : "Doujinshi de bottakuru tsumori ne?" yang artinya, "Kamu bermaksud membantu Luke ya?" dengan maksud ingin mendapatkan jawaban berupa "ya" atau "tidak". Namun karena pertanyaan itu sedikit memalukan untuk Haruko maka dia mejawab dengan tuturan (29) : "Chotto.. Nandemonai kara, nandemonai. Sst!" yang artinya “Em.. Bukan apa-apa kok, bukan apa-apa. Sst!”. Tuturan ini 
melanggar maksim relevansi karena jawaban yang diberikan Haruko sama sekali tidak memliki relevansi dengan pertanyaan yang diberikan Ellen, dan melanggar maksim Cara karena jawaban yang diberikan Haruko tidak jelas.

Pelanggaran maksim relevansi dan maksim Cara tersebut meiliki alasan bahwa Haruko merasa malu dengan pertanyaan Ellen, lalu merespon pertanyaan Ellen dengan kalimat yang mengisyaratkan Ellen agar diam.

\section{Data 10}

Luke : "Boku no hyoujungo tsumetai kara desu ka?" (30) Apakah karena bahasa Jepang standarku terkesan dingin?

Haruko : "Hyoujungo?" (31)

Bahasa Jepang standar?

Situasi percakapan:

Percakapan berlangsung di sebuah kafe tempat Luke bekerja. Luke sedang mengalami patah hati karena dia tidak percaya diri untuk berbiCara dengan wanita yang dia sukai. Dia bertanya pada Haruko mengapa sepertinya wanita yang dia sukai tidak ingin berbiCara dengannya.

Analisis :

Tuturan Haruko (31) : "Hyoujungo?" bisa dikatakan melanggar maksim kuantitas. Luke bertanya pada Haruko mengenai alasan mengapa wanita yang disukai Luke terlihat seperti menghindari Luke dan tidak ingin berbiCara dengannya. Dia mengira alasannya adalah karena kemampuan bahasa Jepang Luke yang kurang, (30) : "Boku no hyoujungo tsumetai kara desu ka?” yang artinya, “Apakah karena bahasa Jepang standarku terkesan dingin?”. Dengan begitu Luke membutuhkan jawaban berupa "benar" atau "bukan". Tetapi Haruko sedikit bingung dengan pertanyaan Luke yang menggunakan kata "houjungo" atau bahasa Jepang standar, sehingga Haruko tidak menjawab "benar" atau "bukan" melainkan kembali bertanya "houjungo" seperti apa yang dimaksud Luke. Tuturan Haruko (31) : "Houjungo" yang artinya "Bahasa Jepang standar?” ini melanggar maksim kuantitas karena jawaban yang diberikan Haruko tidak informatif. Tidak menjawab "benar" atau "bukan" tetapi justru memberika pertanyaan kembali pada Luke. 
Pelanggaran maksim kuantitas tersebut memiliki alasan bahwa Haruko tidak mengerti dan ingin memastikan kembali houjungo seperti apa yang dimaksud Luke sebelum menjawab pertanyaanya.

\section{Data 11}

Haruko : : "Luke, kore mite." (memberikan selembar kertas) (32) Luke, lihatlah ini.

Luke : (melihat kertas yang diberikan Haruko, tapi tidak mengerti isi dari kertas itu)

Haruko : "Kokuhaku no serifu. Kono toori ni ieba daijoubu dakara." (33) Ini adalah kata-kata untuk mengungkapkan perasaan. Jika kamu mengatakan sesuai dengan teks ini, semua akan baik-baik saja.

Katori : : "Hontouni daijoubu desu ka?" (34) Apakah benar-benar tidak apa-apa?

Haruko : : "Atashi wo dare da to omotten no yo? Renai masuta ga ruka no tame ni hito hada nuida no yo." (35) Kamu pikir siapa aku? Ahli percintaan ini sedang melakukan apapun untuk membantu Luke.

Situasi percakapan :

Percakapan berlangsung di dalam sebuah kafe tempat Luke bekerja. Luke yang sedang bingung bagaimana Cara mengungkapkan perasaan sukanya kepada wanita yang dia sukai, meminta bantuan kepada Haruko. Haruko datang ke kafe tempat Luke bekerja bersama katori, teman sesama guru. Mereka sedang memikirkan Cara yang bagus untuk mengungkapkan perasaan Luke kepada wanita yang disukainya.

Anailis :

Tuturan Haruko (35) : "Atashi wo dare da to omotten no yo? Renai masuta ga ruka no ni hito hada nuida no yo." bisa dikatakan melanggar maksim kuantitas. Haruko memberikan selembar kertas yang berisi teks untuk mengungkapkan perasaanya kepada wanita yang dia sukai. Pada tuturan (33) : "Kokuhaku no serifu. Kono toori ni ieba daijoubu dakara." yang artinya, "Ini adalah kata-kata untuk mengungkapkan perasaan. Jika kamu mengatakan sesuai dengan teks ini, semua akan baik-baik saja.", dia menjamin pengakuan cinta Luke akan berjalan dengan lancar jika dia mengatakan sesuai dengan teks yang diberikan Haruko. Katori yang merasa khawatir kemudian bertanya pada tuturan (34) : "Hontouni daijoubu desu ka?" yang 
artinya, "Apakah benar-benar tidak apa-apa?". Pertanyaan katori sebenarnya hanya membutuhkan jawaban "baik-baik saja" atau "tidak baik-baik saja". Haruko yang sangat yakin semuanya akan baik-baik saja tidak menjawab dengan benar melainkan melontarkan kalimat (35) : "Atashi wo dare da to omotten no yo? Renai masuta ga ruka no ni hito hada nuida no yo." yang artinya Kamu pikir siapa aku? Ahli percintaan ini sedang melakukan apapun untuk membantu Luke." Tuturan Haruko tersebut melanggar maksim kuantitas karena respon yang diberikan Haruko lebih infirmatif dari yang dibutuhkan Katori. Katori hanya ingin tahu apakah semua benar-benar akan baik-baik saja, tetapi Haruko justru memberikan jawaban yang panjang lebar kepada Katori.

Pelanggaran maksim kuantitas tersebut memiliki alasan bahwa Haruko ingin membuat Katori percaya padanya. Dia mengatakan bahwa dia adalah ahli percintaan dan dia sedang berusaha sebisa mungkin utuk membantu Luke.

\section{Data 12}

Jack : "Soko de mimi wo hikichigirareta no da to suru to, kono hanashi no taitoru wa "Mimi Nashi Houchi" dewa okashii no dewa?" (36) Jika telinganya ditarik di situ, bukankah aneh jika judul cerita ini "Houichi Tanpa Telinga"?

Haruko : :Do iu imi?" (37) Bagaimana maksudnya?

Situasi percakapan :

Haruko sedang mengajar di kelas saat musim panas. Lalu murid bernama Kinrei bertanya padanya mengapa di TV Jepang saat musim panas selalu ada film menakutkan. Dia menjawab karena cuaca sangat panas, saat kita ketakutan maka akan terasa sedikit dingin. Kemudian salah satu murid menyuruh Haruko untuk menceritakan cerita yang menyeramkan di kelas karena saat itu cuaca sedang sangat panas. Saat Haruko sedang bercerita, di tengahtengah cerita murid bernama Jack bertanya pada Haruko menenai keanehan judul cerita yang disampaikan Haruko

Analisis :

Tuturan Haruko (37) : "Do iu imi?" bisa dikatakan melanggar maksim kuantitas. Jack bertanya pada Haruko pada tuturan (36) : "Soko de mimi wo hikichigirareta no da to suru to, 
kono hanashi taitoru wa "Mimi Nashi Houchi" dewa okashii no dewa?" yang artinya "Jika telinganya ditarik di situ, bukankah aneh jika judul cerita ini “Houichi Tanpa Telinga”?". Dengan begitu Jack memerlukan jawaban berupa pendapat Haruko mengenai apakah cerita itu aneh atau tidak dan penjelasan mengapa demikian. Namun Haruko yang tidak mengerti maksud dari pertanyaan Jack tidak bisa menjawab sesuai keinginan Jack. Dia justru kembali bertanya kepada Jack pada tuturan (37) : "Do iu imi?" yang artinya "Bagaimana maksudnya?". Tuturan ini melanggar maksim kuantitas karena jawaban yang diberikan Haruko atas pertanyaan Jack tidak informatif seperti yang dibutuhkan Jack.

Pelanggaran maksim kuantitas tersebut memiliki alasan berupa Haruko tidak mengerti maksud pertanyaan Jack tentang keanehan judul cerita "Houichi Tanpa Telinga" karena di tengah-tengah cerianya Jack tiba-tiba memotong dan bertanya.

\section{Data 13}

\begin{tabular}{|c|c|}
\hline Haruko & $\begin{array}{l}\text { : "Doushite koko ni?" (38) } \\
\text { Mengapa kalian ada di sini? }\end{array}$ \\
\hline Shibuya & $\begin{array}{l}\text { "lya, katoriinu sensei kara sakki renraku attan dayo." (39) } \\
\text { Tadi kita mendapat pesan dari Cathrine. }\end{array}$ \\
\hline Takasu & $\begin{array}{l}\text { :De, kite mitara nanda yo kore wa? Omae nani asonden dayo?" } \\
\text { (40) } \\
\text { Jadi, apa-apaan ini? Apa yang sedang kalian lakukan? }\end{array}$ \\
\hline Haruko & $\begin{array}{l}\text { :li jan, betsuni. Minna de kaidan banashite suzundetan desu." } \\
\text { (41) } \\
\text { Bukan apa-apa kok. Kita semua sedang menceritakan cerita } \\
\text { menyeramkan. }\end{array}$ \\
\hline
\end{tabular}

Situasi percakapan :

Percakapan berlangsung pada malam hari di dalam kelas. Haruko, Katori dan muridmuridnya yang sedang membahas cerita menyeramkan dikejutkan oleh kedatangan Shibuya dan Takasu, rekan seperguruannya. Haruko yang masih merasa kaget bertanya kepada mereka bagaimana mereka bisa ada di sana. Ternyata Katori lah yang memberi pesan kepada Shibuya. Kemudian Takasu yang merasa marah bertanya pada Haruko apa yang dia dan murid-muridnya lakukan di dalam kelas padahal hari sudah malam. Terlebih lagi, di dalam kelas itu mereka 
menyalakan banyak lilin dan memasang berbagai macam hiasan bernuansa halloween yang membuat Takasu semakin bingung.

Analisis :

Tuturan Haruko (41) : "Ii jan, betsuni. Minna de kaidan banashite suzundetan desu." bisa dikatakan melanggar maksim kuantitas. Takasu yang kebingungan bertanya pada Haruko pada tuturan (40) : "De, kite mitara nanda yo kore wa? Omae nani asonden dayo?" yang artinya, “Jadi, apa-apaan ini? Apa yang sedang kamu lakukan?”. Pertanyaan itu membutuhkan jawaban berupa apa yang sedang Haruko dan murid-muridnya lakukan, yaitu membahas cerita menyeramkan. Namun jawaban yang diberikan Haruko justru melebihi jawaban yang seharusnya. Pada tuturan (41) :"li jan, betsuni. Minna de kaidan banashite suzundetan desu." yang artinya "Bukan apa-apa kok. Kita semua sedang menceritakan cerita menyeramkan.", dia menambahkan kalimat :"li jan, betsuni." yang artinya "Bukan apa-apa kok", kalimat itu adalah informasi yang tidak dibutuhkan Takasu atas pertanyaannya. Seharusnya Haruko menjawab dengan "Minna de kaidan banashite suzundetan desu." saja yang artinya "Kita semua sedang menceritakan cerita menyeramkan." Dengan demikian tuturan Haruko melanggar maksim kuantitas karena jawaban yang Haruko berikan lebih informatif dari yang seharusnya dibutuhkan Takasu.

Pelanggaran maksim kuantitas tersebut memiliki alasan bahwa Haruko ingin menegaskan bahwa Takasu tidak perlu marah-marah. Dia ingin menjelaskan dan menegaskan bahwa dia dan murid-muridnya hanya sedang membahas cerita menyeramkan di dalam kelas. Dengan kata lain mereka tidak membuat keributan.

\section{Data 14}

Takasu : "Mimawari touban wa omae datta yo na?" (42) Bukankah sekarang adalah giliranmu untuk tugas berkeliling?

Haruko : (melihat sekeliling dengan wajah panik)

Takasu : "Are, are? Kowai no?" (43) Loh loh? Kamu takut?

Haruko : "Waktatta wa yo! Ikeba iin deshou, ikeba!" (44) Baiklah! Lebih aku harus pergi kan, harus pergi!

Situasi percakapan : 
Percakapan berlangsung pada malam hari di dalam kelas. Saat Takasu sedang menceritakan kisah menyeramkan tentang bagaimana huruf kanji bisa terbentuk, tiba-tiba hawa dinging terasa di ruang kelas itu. Semua orang merasakan kedinginan itu. Katori megatakan bahwa dia pernah merasakan seperti ini saat berjalan di lorong pada malam hari. Kemudian takasu berkata pada Haruko bahwa hari ini adalah giliran Haruko untuk tugas berkeliling.

Analisis :

Tuturan Haruko (44) : "Waktatta wa yo! Ikeba iin deshou, ikeba!" bisa dikatakan melanggar maksim relevansi dan maksim kuantitas. Pertanyaan Takasu pada tuturan (43) : "Are, are? Kowai no?" yang artinya "Loh loh? Kamu takut?" hanya membutuhkan jawaban berupa "takut" atau "tidak takut". Namun Haruko tidak memberikan jawaban itu melainkan menjawab dengan tuturan (44) : "Waktatta wa yo! Ikeba iin deshou, ikeba!" yang artinya "Baiklah! Lebih aku harus pergi kan, harus pergi!" . Jawaban itu tidak informatif seperti yang dibutuhkan Takasu dan tidak relevan dengan pertanyaan Takasu. Dengan jawaban yang diberika Haruko tersebut, tidak jelas apakah dia takut atau tidak. Tuturan ini melanggar maksim relevansi karena jawaban Haruko dan pertanyaan Takasu tidak relevan. Saat Takasu bertanya apakah Haru takut, Haruko menjawab dengan kalimat yang menyatakan dia akan pergi. Sedangkan pelanggaran maksim kuantitas dikarenakan jawaban yang diberikan Haruko tidak informatif, maksudnya dengan jawaban yang diberikan Haruko, Takasu tidak mendapatkan informasi akan takut atau tidaknya Haruko.

Pelanggaran maksim relevansi dan kuantitas ini memiliki alasan bahwa Haruko tidak ingin terlihat takut walaupun dia sebenarnya takut. Dia ingin menegaskan kepada Takasu bahwa dia tidak takut dan dia akan melaksanakan tugas berkelilingnya.

\section{Data 15}

Mary : "Jugyou wa ureshiku yarimasenka?"(45) Apakah kamu tidak mengajar dengan gembira?

Haruko : "Ureshiku' ja nakute, 'tanoshiku' desu." (46) Bukan 'dengan gembira' tapi 'dengan senang'.

Situasi percakapan 
Percakapan berlangsung saat Haruko sendang mengevaluasi hasil tes bahasa Jepang murid-muridnya di kelas. Karena hampir semua muridnya membuat kesalaha, dia memulai pelajaran dengan suasan hati yang sedikit buruk. Saat salah satu muridnya berkata bahwa dia menakutkan, dia membantah bahwa dia tidak meneakutkan. Walaupun begitu dia menjawab dengan nada marah. Lalu murid bernama Mary menanyainya apakah dia tidak senang dengan pelajran hari ini. Dia bertanya karena tidak biasanya Haruko memulai pelajaran dengan suasana hati yang buruk.

Analisis :

Tuturan Haruko (46) : "'Ureshiku' ja nakute, 'tanoshiku' desu." bisa dikatakan melanggar maksim kuantitas dan maksim Cara. Pertanyaan Mary seharusnya hanya membutuhkan jawaban gembira atau tidaknya Haruko, namun karena penggunaan kata yang Mary gunakan salah, Haruko tidak menjawab pertanyaan Mary melainkan membenarkan kalimat pertanyaannya. Pada tuturan (45) : "Jugyou wa ureshiku yarimasenka?" yang artinya, "Apakah kamu tidak mengajar dengan gembira?", Mary menggunakan kata 'ureshiku' yang artinya sama dengan kata 'tanoshiku'. Tetapi walaupun sama artinya, konteks pemakaiannya berbeda. Mary seharusnya menggunakan kata 'tanoshiku' untuk kalimat petnanyaanya. Haruko yang ingin mengetahui bahwa kalimat itu salah langsung memberi tahu Mary bagaimana kalimat yang benar tanpa menjawab pertanyaan Mary terlebih dahulu. Pada tuturan (46) : " 'Ureshiku' ja nakute, 'tanoshiku' desu." yang artinya "Bukan 'dengan gembira' tapi 'dengan senang'." Haruko menjelaskan bahwa Mary salah menggunakan kata 'ureshiku' dan harus diganti dengan 'tahoshiku'. Tuturan ini melanggar maksim kuantitas karena jawaban yang diberikan Haruko tidak informatif. Dia tidak menjawab gembira atau tidak, justru membenarkan pertanyaan Mary. Sedangkan pelanggaran maksim Cara dikarenakan Jawaban Haruko atas pertanyaan Mary tidak jelas maknanya dan mengandung ketaksaan. Marry bisa saja salah paham dengan Jawaban yang diberikan Haruko. Dia bisa saja mengira bahwa Haruko hanya menjawab pertanyaanya, bukan membenarkan kesalahannya.

Pelanggaran maksim kuantitas dan maksim Cara tersebut memiliki alasan bahwa Haruko ingin memberi tahu Mary bahwa yang seharusnya dia gunakan adalah kata 'tanoshiku' bukan 
'ueshiku'. Dia langsung membenarkan kalimat tanya Mary karena menurutnya dia sudah pernah membahas materi itu di kelas, namun Mary masih mengulangi kesalahan yang sama.

\section{Data 16}

Ellen : "Haruko, 'shibobi' to 'kunoichi' mo imi ga chigau?" (47) Haruko, apakah 'shinobi' dan 'kunoichi' artinya berbeda?

Haruko : "Sou iu shitsumon ha jugyou ga owatte kara." (48)

Kamu bisa bertanya tentang itu setelah pelajaran selesai.

Situasi percakapan:

Percakapan berlangsung di dalam kelas saat Haruko sedang memberikan evaluasi tes bahasa Jepang kepada murid-muridnya. Mereka sedang membahas kesalahan-kesalahan yang dibuat oleh murid-muridnya. Haruko marah karena dia sudah mengajarkan semua materi yang ada di doal tes, namun murid-muridnya masih saja membuat kesalahan yang sama. Di tengahtengah evaluasi, murid bernama Ellen menanyakan pertanyaan yang di luar konteks pelajaran. Karena saat itu suasana Haruko sedang buruk, dia merespon pertanyaan Ellen dengan dingin. Analisis :

Tuturan Haruko (48) : "Sou iu shitsumon ha jugyou ga owatte kara." bisa dikatakan melanngar maksim relevansi. Di tengah-tengan evaluasi yang sedang diberkan Haruko, murid bernama Ellen bertanya padanya mengenai ninja, perbedaan santar 'shinobu' dan 'kunoichi', yang mana tidak ada kaitannya dengan evaluasi yang sedang diberikan Haruko. haruko yang sudah marah karena kesalahan yang dibuat murid-muridnya menjawab pertanyaan Ellen dengan dingin, (48) : "Sou iu shitsumon ha jugyou ga owatte kara." yang artinya "Kamu bisa bertanya tentang itu setelah pelajaran selesai." Tuturan ini melanggar maksim relevansi karena jawaban yang diberikan haruko tidak relevan atau tidak berhubungan dengan pertanyaan Ellen. Haruko tidak menjawab apakah 'shinobi' dan 'kunoichi' berbeda, melainkan memberi peringatan pada Ellen untuk berntanya setelah pelajaran selesai.

Pelanggaran maksim relevansi tersebut memiliki alasan bahwa Haruko merasa terganggu dengan pertanyaan Ellen yang di luar topik pelajaran. Dia ingin memberi tahu Ellen bahwa saat itu bukanlah saat yang tepat untuk bertanya mengenai ninja, dan dia tidak seharusnya bertanya tentang ninja di dalam kelas saat pelajaran sedang berlangsung. 


\section{Data 17}

Shibuya : "Nee nee, jugyouchuu nani donatteta no?" (49)

Hei hei, apa yang kamu teriakkan selama pelajaran tadi?

Haruko : : "Mou sa, seito koukan shinai? Mou atashi kono mama ja isssho

koukou kyoushi ni narenai kara ne." (50)

Aduh.. kamu mau bertukar murid denganku? Kalau terus seperti

ini aku tidak akan pernah bisa jadi guru SMA.

Situasi percakapan :

Percakapan antara Haruko dan Shibuya berlangsung di lorong sekolah saat mereka berdua baru saja selesai mengajar. Shibuya mendengar Haruko berteriak-teriak saat mengajar tadi, dia penasaran mengapa Haruko bisa sampi berteriak seperti itu dan apa yang membuatnya berteriak.

Analisis :

Tuturan Haruko (50) : bisa dikatakan melanggar maksim relevansi dan kuantitas. Shibuya menanyakan alasan mengapa Haruko berteriak selama mengajar, dengan begitu pertanyaan Shibuya membutuhkan jawaban berupa alasan atau penjelasan mengapa Haruko berteriak. Namun Haruko yang masih kesal dengan murid-muridnya justru tidak memberi jawaban yang pas kepada Shibuya melainkan memberikan jawaban (50) yang artinya "Aduh.. kamu mau bertukar murid denganku? Kalau terus seperti ini aku tidak akan pernah bisa menjadi guru SMA." Pada tuturan ini dia mengutarakan bahwa dia inin bisa bertukar murid dengan Shibuya. Dia juga merasa dia tidak akan bisa menjadi guru SMA jika terus mengajar murid-muridnya sekarang. Tuturan tersebut melanggar maksim relevansi karena jawaban Haruko tidak relevan dengan pertanyaan Shibuya. Dia menjawab dengan ocehan mengenai kekhawatirannya pada murid-muridnya. Tuturan tersebut juga melanggar maksim kuantitas karena jawaban yang diberikan Haruko terlalu panjang-lebar dan tidak informatif seperti yang dibutuhkan Shibuya.

Pelanggaran maksim relevansi dan maksim kuantitas ini memiliki alasan bahwa Haruko sedang kesal dengan murid-muridnya dan dia ingin bercerita pada Shibunya mengenai keluhannya. 


\section{Data 18}

Fumio : : "Zutto koko de yatteku tsumori ka?" (51)

Kamu berencana terus mengajar di sini?

Haruko : : "Masaka. Mada akirametenai shi." (52)

Masa. Aku masih belum menyerah.

Situasi percakapan

Percakapan berlangsung di depan ruang guru saat Fumio, mantan kekasih Haruko, menemuinya di sekolah tempat Haruko mengajar. Mereka berbincang mengenai mengajar di SMA. Fumio meremehkan sekolah tempat Haruko mengajar karena tempat itu adalah sekolah khusus untuk orang-orang asing. Dia bertanya pada Haruko apakah Haruko ingin terus bekerja di sekolah ini.

Analisis :

Tuturan haruko (52) : "Masaka. Mada akirametenai shi." bisa dikatakan melanggar maksim relevansi. Fumio bertanya pada tuturan (51) : 'Zutto koko de yatteku tsumori ka?" yang artinya "Kamu berencana terus mengajar di sini?". Pertanyaan itu membutuhkan jawaban 'ya' atau 'tidak', namun Haruko tidak menjawab dengan benar melainkan menjawab dengan tuturan (52) yang artinya Masa. Aku masih belum menyerah". Tuturan ini melanggar maksim relevansi karena apa yang ditanyakan Fumia dan jawaban yang diberikan Haruko tidak relevan. Dia hanya memberikan jawaban bahwa dia belum menyerah.

Pelanggaran maksim relevansi ini memiliki alasan bahwa Haruko ingin menegaskan pada Fumio bahwa dia tidak akan selamanya mengajar di sekolah ini. Dia bercita-cita menjadi guru SMA dan dia belum menyerah dengan cita-cita itu.

\section{Data 19}

Ellen : (mengambil buku dari tangan hruko) "Ja, tetsudau. Mazu... kore nante yomu de gozaru ka?" (53)

Baik, aku akan membantu. pertama... ini huruf apa ya?

Haruko : "Fufu.. wakaranakattara tetsudawanakute mo ii kara ne." (54) Hehe.. kalau kamu tidak tahu, tidak usah membatu juga tidak apa-apa kok.

Situasi percakapan : 
Percakapan berlangsung di dalam ruang kelas saat Haruko sedang menjelaskan tataCara upaCara minum teh (chakai). Dia ingin membantu Jack yang sedang ingin berlatih tata Cara upacara minum teh, tetapi murid-murid lain mengganggunya.

Analisis :

Tuturan Haruko (54) : bisa dikatakan melanggar maskim relvansi. Ellen bertanya mengenai huruf yang tidak dia mengerti dalam buku tata Cara upaCara minum teh. Namun haruko tidak memberi tahunya huruf apa itu, melainkan menjawab dengan tuturan (54) yang artinya, "Hehe.. kalau kamu tidak tahu, tidak usah membatu juga tidak apa-apa kok". Tuturan ini melanggar masksim relevansi karena jawaban Haruko tidak relevan dengan pertanyaan Ellen. Ellen membutuhkan jawaban berupa bagaimana Cara baca huruf yang dia tanyakan, tetapi Haruko tidak memberinya jawaban yang tepat melainkan memberi tahu Ellen bahwa dia tidak perlu membantu.

Pelanggaran maskim relevansi tersebut mempunyai alasan bahwa Haruko tidak membutuhkan bantuan dari Ellen ataupun murid lainnya. Dia sedang ingin berkonsentrasi membantu Jack mempelajari upaCara minum teh, tetapi Ellen dan murid-murid lain terus mengganggunya dan berkata ingin membantu. karena itu Haruko berkata bahwa Ellen tidak perlu membantu.

Data 20

Haruko : :Kiki dashite ageyou ka?" (55) Mau aku tanyakan?

Takasu : "He?” (56)

$\mathrm{Hm}$ ?

Haruko : : "Ano ko ga koko ni kota riyuu." (57)

Alasan mengapa anak itu datang ke sini

Takasu : "Sonna koto dekiru no ka yo?" (58)

Apa kamu bisa melakukan itu?

Haruko : : “Dekirun desu ka Haruko Sensei?” (59)

Apakah Anda bisa, Ibu guru Haruko?

Situasi percakapan :

Percakapan berlangsung di depan ruang guru. Haruko dan Takasu sedang membiCarakan putri Takasu yang datang ke tempat dia mengajar. Dia ingin tahu alasan 
mengapa putrinya datang menemuinya, tetapi dia tidak berani bertanya karena dia sudah sepuluh tahun berpisah. Lalu Haruko menawarkan bantuan kepada Takasu bahwa Haruko akan menanyakan pertanyaan Takasu kepada putrinya.

Analisis :

Tuturan Haruko (59) : “Dekirun desu ka Haruko Sensei?” bisa dikatakan melanggar maksim relevansi. Haruko menawarkan bantuan kepada Takasu bahwa dia akan bertanya pada putrinya. Namun Takasu yang tidak percaya pada Haruko menanyakan kembali apakah dia benar-benar akan melakukannya. Tuturan Takasu (58) : "Sonna koto dekiru no ka yo?" yang artinya, “Apa kamu bisa melakukan itu?” hanya membutuhkan jawaban 'bisa' atau 'tidak bisa', tetapi Haruko yang merasa diremehkah justru mengejek Takasu dengan membenarkan Cara bertanyanya (59) : “Dekirun desu ka Haruko Sensei?” yang artinya “Apakah Anda bisa, Ibu guru Haruko?" tuturan ini melanggar maksim relevansi karena jawaban yang diberikan Haruko tidak relevan dengan pertanyaan Takasu. Tidak menjawab dengan 'bisa' atau 'tidak bisa', Haruko justru membenarkan Cara bertanya Takasu.

Pelanggaran maksim relevansi tersebut mempunyai alasan bahwa Haruko ingin mengejak Takasu yang sedang kebingungan. Biasanya Haruko lah yang diejek oleh Takasu, saat itu karena Takasu sedang kebingungan menghadapi putrinya, Haruko dengan sengaja mengejeknya. Dia mengejek dengan Cara membenarkan dan mengulang pertanyaan Takasu. Pada kalimat itu, dia membenarkan bahwa saat meminta tolong pada sseorang, Takasu harus menggunakan bahasa sopan, bukan bahasa sehari-hari.

\section{Data 21}

Takasu : :Kurasu zenin sotsugyou shiken ni goukaku dekinakattara, koukou koushi no yume wa akiramerun datta yo na?" (60) Kalau kamu tidak bisa meluluskan semua murid di tes kelulusan, kamu akan menyerah pada mimpimu untuk menjadi guru SMA bukan?

Haruko : "Kono sai, zenin goukaku de yokunai?" (61)

Dengan hasil ini, bukankah bagus jika semua muridku lulus?

Situasi percakapan : 
Percakapan berlangsung di dalam ruang guru saat Takasu sedang membagian hasil tes murid-murid kepada para guru. Kelas haruko adalah kelas paling buruh di antara yang lain. Dalam kelasnya hanya ada sati dari sembilan orang murid yang mendapat kemungkinan lulus pada tes kelulusan. Lalu Takasu mengingatkan Haruko tentang janji yang sudah dia buat di hari pertama dia mengajar di sekolah itu, yaitu jika semua muridnya tidak bisa lulus bersama, dia akan menyerah pada mimpinya untuk menjadi guru SMA.

Analisis :

Tuturan Haruko (61) : “Kono sai, zenin goukaku de yokunai?” bisa dikatakan melanggar maksim relevansi. Takasu bertanya pada Haruko mengenai janji yang dibuatnya, apakah dia akan menyerah atau tidak. Dengan demikian dia membutuhkan jawaban berupa Haruko akan menrah atau tidak. Namun Haruko tidak ingin membahas mengenai janji itu, maka dia mengalihkan pembiCaraan dengan bertanya apakah ada kemungkinan kelasnya akan lulus dengan hasil yang saat itu dia dapatkan. Tuturan (61) melanggar maksim relevansi karena jawaban yang diberikan Haruko tidak relevan dengan petanyaan Takasu.

Pelanggaran maksim relevansi tersebut mempunyai alasan bahwa Haruko merasa malu mengakui janjinya. Dia tidak ingin menyerah akan mimpinya, dia ingin berusaha tetapi keadaan kelasnya tidak memungkinkan untuk mereka bisa lulus di tes kelulusan.

\section{Data 22}

Jack : " "Haruko, jugyou wo hajimete kusadai." (62) Haruko, tolong mulai pelajarannya.

Haruko : (diam)

Jack : "Doushimasu ka?" (63)

Ada apa?

Haruko : "Ah.. minna, koko made benkyou shite kite doutatta?" (64)

Ah.. Anak-anak, bagaimana bahasa Jepang yang sudah kalian pelajari sampai saat ini?

Situasi percakapan

Percakapan berlangsung di kelas saat Haruko akan memulai kelas tambahan. Haruko yang sebenarnya hanya ingin menyampaikan pengumuman bahwa dia berhenti menjadi guru, bingung memulai dari mana. Saat Jack meminta Haruko memulai pelajaran, dia Hanya berdiri 
diam sambil memikirkan kata-kata apa yang sebaiknya dia ucapkan. Jack yang penasaran karena Haruko hanya diam kemudian bertanya apa yang terjadi. Namun Haruko tidak ingin membuat murid-muridnya khawatir, maka dia mengalihkan pembiCaraan.

Analisis :

Tuturan haruko (64) : Ah.. minna, koko made benkyou shite kite doutatta?" bisa dikatakan melanggar maksim kuantitas. Pertanyaan Jack (63) membutuhkan jawaban berupa alasan mengapa Haruko tidak kunjung memulai pelajaran. Namun Haruko tidak memberikan tahu Jack alasannya, melainkan mengalihkan pembiCaraan dengan tuturan (64) yang artinya, “Ah.. Anak-anak, bagaimana bahasa Jepang yang sudah kalian pelajari sampai saat ini?”. Dia bertanya kepada murid-muridnya tentang bagaimana pendapat mereka mengenai bahasa Jepang yang selama ini mereka pelajari. Tuturan ini melanggar maksim kuantitas karena jawaban yang diberkan Haruko tidak informatif. Dengan respon Haruko, Jack tetap tidak mengerti apa yang membuat Haruko tidak langsung memulai pelajaran pada saat itu.

Pelanggaran maksim kuantitas tersebut memiliki alasan bahwa Haruko sedang berbasa basi dengan murid-muridnya. Dia ingin menyampaikan pengumuman bahwa dia berhenti mengajar mulai saat itu, namun dia tidak tahu harus memulai dari mana, maka dari itu dia berbasa basi dengan menyanyakan bahasa Jepang yang selama ini mereka pelajari.

\section{Data 23}

Mary : "Haruko ga suki na nihongo wa nan desu ka?" (65) Apa bahasa Jepang yang kamu sukai, Haruko?

Murid : "Oshiete yo!"

Beri tahu kami!

Haruko : : "Sore yori, kyou wa minna ni itte okanakya ikenai koto ga aru no. Jitsu wa. kyou de gakkou yameru koto ni narimashita." (66) Dari pada itu, hari ini aku punya hal yang harus kukatakan pada kalian semua. Sebenarnya aku sudah berhenti mengajar mulai hari ini."

Situasi percakapan :

Percakapan berlangsung di dalam kelas saat pelajaran tambahan. Setelah berbasa basi mengenai bahasa Jepang yang murid-muridnya pelajari sampai saat ini, Haruko menanyakan 
kalimat bahasa Jepang apa yang mereka sukai. Semua murid sudah menjawab. Lalu Mary bertanya pada Haruko mengenai bahasa Jepang yang Haruko sukai.

Analisis :

Tuturan Haruko (66) : "Sore yori, kyou wa minna ni itte okanakya ikenai koto ga aru no. Jitsu wa.. kyou de gakkou yameru koto ni narimashita." bisa dikatakan melanggar maksim kuantitas dan relvansi. Haruko mengabaikan pertanyaan Mary yang bertanya mengenai kalimat bahasa Jepang apa yang Haruko sukai. Dia tidak menjawabnya, melainkan berkata pada tuturan (66) yang artinya "Dari pada itu, hari ini aku punya hal yang harus kukatakan pada kalian semua. Sebenarnya aku sudah berhenti mengajar mulai hari ini." Dia yang semula bingung bagaimana Cara mengawali pengumumanna, akhirnya memberikan pengumuman bahwa dia akan berhenti mengajar. Tuturan ini melanggar maksim kuantitas karena jawaban yang Haruko berikan tidak informatif seperti yang diinginkan Mary dan murid lainnya. Dan melanggar maksim relevansi karena jawaban yang dberikan Haruko tidak relevan dengan pertanyaan Mary. Mary bertanya bahas Jepang apa yang Haruko sukai, namun Haruko tidak merespon pertanyaan itu, melainkan memberikan pengumuman mengejutkan.

Pelanggaran maskim kuantitas dan maksim relevansi tersebut memiliki alasan bahwa Haruko merasa saat itu adalah saat yang tepat untuk memberi pengumuman berhentinya dia. Awalnya dia kebingungan mengawali pengumumannya, setelah berbasa basi sedikit, akhirnya dia menyampaikan pengumuman yang ingin dia sampaikan itu

\section{Simpulan}

Hasil analisis penelitian implikatur percakapan pada respon verbal tokoh Hruko dalam drama Jepang Nihonjin no Shiranai Nihongo karya Yoshihiro Izumi, dari episode satu sampai dua belas ditemukan 23 respon Haruko yang mengandung implikatur karena melanggar maksim-maskim prinsip kerjasama Grice. Dalam 23 respon yang mengandung implikatur tersebut, terdapat pelanggaran maksim tunggal sebanyak 14 tuturan, dan pelanggaran maksim ganda sebanyak 9 tuturan. Pelanggaran maksim tersebut antara lain, 5 tuturan melangar maksim kuantitas, 7 tuturan melanggar maksim relevansi, dan 2 tuturan melanggar maksim cara, 4 tutura melanggar maksim relevansi dan cara, 1 tuturan melanggar maksim kualitas dan 
kuantitas, 3 tuturan melanggar maksim kuantitas dan relevansi, 1 tuturan melanggar maksim kuantitas dan cara. Pelanggaran-pelanggaran maksim tersebut menimbulkan implikatur. Adapun alasan dari setiap pelanggaran tersebut bermacam-macam, misalnya karena Haruko adalah guru baru, maka dia masih punya banyak kekurangan dan sering tidak bisa menjawab pertanyaan murid-muridnya yang beragam. Karena itu lah mulai timbul berbagai masalah di dalam kelas yang diajarnya. Berdasarkan analisis data, pelanggaran-pelanggaran maksim tersebut meliliki berbagai maksud, antara lain pada tuturan (18), (24), (47), (51), (62), penutur ingin memberikan informasi. Pada tuturan (3), (14), (20), penutur ingin meminta informasi. Pada tuturan (44), (8), penutur ingin menghindar atau tidak bisa menjawab pertanyaan. Pada turutan (26), (53) penutur ingin mengekspresikan kemarahan. Tuturan (12), (28), (28) penutur ingin mempertegas tuturan. Pada tututan (57), (60), penutur merasa malu. Pada tururan (37), (40), (64), (66), penutur ingin mengalihkan pembicaraan. Pada tuturan (30), penutur ingin memperhalus tuturan. Dan pada tuturan (35), penutur ingin mengejek lawan bicara.

\section{Daftar Pustaka}

Astuti, Tri. (2011). Implikatur Percakapan Tokoh Chieko dalam Novel Koto Karya Yasunari Kawabata. (Skripsi) Semarang : FIB Udinus.

Grice, H.P. (1991). Logic and Conversation. New York: Oxford University Press.

Levinson, Stephen. C. (1983). Pragmatic. Great Britain: Cambridge Unuversity Press.

Matsuura Kenji. (2005). Kamus Jepang Indonesia. Jakarta: Gramedia Pustaka Utama.

Perwira, Ahmad Sandy. (2017). Implikatur Percakapan Tokoh Fukamachi Yousuke Sebagai Tokoh Utama dalam Novel Kimi ga Denwa wo Kaketa Basho. (Skripsi) Semarang : FIB Udinus.

Rahmawati, Fadhilah. (2009). Implikatur Komik Doraemon : Pendekatan Pragmatik. (Skripsi) Surakarta : FSSR UNS.

Saifudin, A. (2018). Teori Tindak Tutur dalam Studi Linguistik Pragmatik. Lite: Jurnal Bahasa, Sastra, dan Budaya 15 (1), 1-16

Saifudin, A. (2018). Konteks dalam Studi Linguistik Pragmatik. Lite: Jurnal Bahasa, Sastra, dan Budaya, 14 (2). Semarang.

Saifudin, A. (2005). Faktor Sosial Budaya dan Kesopanan Orang Jepang dalam Pengungkapan Tindak Tutur Terima Kasih pada Skenario Drama Televisi Beautiful Life Karya Kitagawa Eriko. Tesis Program Studi Kajian Wilayah Jepang Program Pascasarjana Universitas Indonesia Jakarta.

Yule, George. (1996). Pragmatik (edisi terjemahan oleh Indah Fajar Wahyuni). Yogyakarta : Pustaka Pelajar. 